\title{
Existing data sources for clinical epidemiology: Scandinavian Cohort for osteonecrosis of the jaw - work in progress and challenges
}

This article was published in the following Dove Press journal:

Clinical Epidemiology

22 January 2015

Number of times this article has been viewed

\author{
Morten Schiodt ${ }^{1}$ \\ Cecilia Larsson Wexell 2,3 \\ Bente Brokstad Herlofson ${ }^{4}$ \\ Karen Marie Giltvedt ${ }^{4}$ \\ Sven Erik Norholt ${ }^{5}$ \\ Vera Ehrenstein ${ }^{6}$ \\ 'Department of Oral and Maxillofacial \\ Surgery, Rigshospitalet, Copenhagen \\ University Hospital, Copenhagen, \\ Denmark; ${ }^{2}$ Department of Oral and \\ Maxillofacial Surgery, Södra Älvsborg \\ Hospital, Region Västra Götaland, \\ Borås, ${ }^{3}$ Department of Biomaterials, \\ Institute of Clinical Sciences, \\ Sahlgrenska Academy, University of \\ Gothenburg, Gothenburg, Sweden; \\ ${ }^{4}$ Department of Oral Surgery and \\ Oral Medicine, Faculty of Dentistry, \\ University of Oslo, Oslo, Norway; \\ ${ }^{5}$ Department of Oral and Maxillofacial \\ Surgery, Aarhus University and \\ University Hospital, ${ }^{6}$ Department \\ of Clinical Epidemiology, Aarhus \\ University Hospital, Aarhus, Denmark
}

Correspondence: Morten Schiodt Department of Oral and Maxillofacial Surgery, Z2002, Rigshospitalet, Copenhagen University Hospital, Blegdamsvej 9, Copenhagen $2100 \varnothing$, Denmark

$\mathrm{Tel}+453545 \quad 880$

Fax +45 35452364

Email morten.schioedt@regionh.dk/ mschioedt@hotmail.com

\begin{abstract}
Osteonecrosis of the jaw (ONJ) is a severe side effect associated with antiresorptive treatment. Monitoring of $\mathrm{ONJ}$ using routine databases in Scandinavian countries is a challenge owing to lack of valid algorithms and to heterogeneous referral practices. The aim of this paper is to describe the process of establishing a Scandinavian ONJ Cohort enrolling all ONJ cases related to antiresorptive treatment arising in Denmark, Norway, and Sweden between 2011 and 2019. The initial purpose of the cohort is to support an ongoing pharmacovigilance study of denosumab and zoledronic acid in Denmark, Norway, and Sweden. The three countries, with their 199 clinics, departments, and units of oral and maxillofacial surgery, both hospital-based and freestanding, differ somewhat in referral practices of the ONJ patients. By directly contacting all providers of care to ONJ patients in the three countries, we established a network for reporting incident cases to each country's research database directly or through a member of the Scandinavian ONJ task force as a liaison. The task force includes a Scandinavian coordinator and three national coordinators collaborating directly with the clinics. A uniform ONJ registration form has been developed, and the relevant medical community has been informed either directly or through presentations at professional meetings. A website with study information is published in each country, and data entry is ongoing. This large-scale systematic uniform registration of ONJ cases in Denmark, Norway, and Sweden, with an underlying total population of more than 20 million people, merged into the Scandinavian ONJ Cohort, will contribute to better knowledge and understanding of this challenging group of patients, and ultimately, help improve patient care. The Scandinavian ONJ Cohort as a whole and its component national ONJ research databases may offer the potential for large-scale multinational intervention and safety studies in the future.
\end{abstract}

Keywords: antiresorptive, bisphosphonate, cancer, classification, denosumab, epidemiology, osteonecrosis, jaws, ONJ, osteoporosis, Scandinavia

\section{Introduction}

Osteonecrosis of the jaw (ONJ) is a severe side effect associated with antiresorptive treatment. ${ }^{1-5}$ In epidemiologic studies, identification of clinically confirmed ONJ has been challenging outside of clinical trial settings because of retrospective ascertainment, poor algorithms, small samples, and lack of adjudication. ${ }^{6-10}$ Further, much remains to be learned about epidemiology, pathogenesis, risk factors, treatment, and prognosis of ONJ. ${ }^{11-14} \mathrm{~A}$ uniform, population-based prospective and systematic registration and follow-up of all clinically confirmed ONJ cases is needed to help fill the current gap in knowledge about this condition and therefore, ultimately serve to improve patient outcomes. This paper describes an international effort to establish the Scandinavian ONJ Cohort enrolling ONJ cases arising in Denmark, Norway, and Sweden between 
2011 and 2019. Use of these data is envisioned for clinical research, surveillance, and pharmacovigilance.

\section{ONJ: definition, epidemiology,} and risk factors

ONJ is diagnosed clinically and is defined by the presence of exposed jaw bone for more than 8 weeks in a patient with a history of antiresorptive treatment and without a history of radiation therapy to the head and neck area. ${ }^{15}$ This definition by the American Association of Oral and Maxillofacial Surgeons (AAOMS) has been adopted by most researchers and clinicians. Another definition by the American Society for Bone and Mineral Research was published in 2007. ${ }^{11}$ This includes "confirmed" ONJ, defined similarly to the AAOMS definition, with an addition of "suspected" ONJ, defined as similar lesions observed for no more than 8 weeks. Such lesions should be followed in order to classify the patients after due observation period. Thus, the two sets of criteria are, for practical purposes, similar, and the AAOMS definition was adopted for the purpose of inclusion into the Scandinavian ONJ Cohort. Severity of ONJ is designated by stages $0-3 .{ }^{16}$ Originally, stages $1-3$ had been defined, ${ }^{15}$ with stage 0 subsequently added to designate ONJ with nonspecific symptoms and without macroscopically exposed bone. ${ }^{16}$ Such "nonexposed ONJ"17-19 accounts for up to $29 \%-45 \%$ of some ONJ case series, ${ }^{17,20}$ and formal criteria for nonexposed ONJ have been recently suggested. ${ }^{19}$ The recent revision of the AAOMS classification of ONJ includes the presence of a fistula, during which the bone can be probed. This is a valuable improvement of the ONJ definition, as failure to classify nonexposed ONJ as true ONJ may cause underestimation of ONJ occurrence in epidemiologic studies. Cases of nonexposed ONJ, including revised ONJ cases with fistula, ${ }^{21}$ are being enrolled in the Scandinavian ONJ Cohort, based on the definition by Schiodt et al. ${ }^{19}$ Recently a new multicenter study of 799 ONJ patients documented that up to one quarter of the patients would remain undiagnosed if non-exposed ONJ are not taken into consideration. ${ }^{22}$

The first published reports of ONJ from $2003^{1}$ and $2004^{2}$ involved, respectively, 119 and 63 patients treated with bisphosphonates. ONJ is mainly associated with antiresorptive therapy, including bisphosphonate ${ }^{23}$ and denosumab. ${ }^{24}$ Both drug classes, via different mechanisms, inhibit osteoclasts and are used to treat tumor-associated bone disease, ${ }^{25,26}$ postmenopausal osteoporosis, ${ }^{27}$ Paget's disease of bone, ${ }^{28}$ and hypercalcemia. ${ }^{29}$ In addition, there is evidence of ONJ being a side effect of the antineoplastic agent sunitinib, a receptor tyrosine kinase inhibitor, ${ }^{30,31}$ and bevacizumab, a monoclonal antibody inhibiting angiogenesis. ${ }^{32-38}$ The risk of ONJ increases with increasing cumulative dose and duration of antiresorptive treatment. ${ }^{39,40}$ Risk estimates over $36-48$ months range from $0.01 \%-0.4 \% \%^{8,10,40}$ in osteoporosis patients to $0.2 \%-20 \%{ }^{39-43}$ in cancer patients, although the estimates are not always based on clinically confirmed cases. Furthermore, the risk of ONJ depends on the type of agent (higher in nitrogen-containing than in non-nitrogencontaining bisphosphonates) and route of administration (higher with intravenous than with oral treatment). ${ }^{40}$ Other possible, although not well established, ${ }^{43}$ risk factors include advanced age, ${ }^{44}$ steroid treatment, ${ }^{43}$ and chemotherapy. ${ }^{43,45}$ Observations suggest that the underlying disease may have a more decisive role than originally assumed.

\section{Terminology of osteonecrosis}

The terminology surrounding the osteonecrosis is somewhat confusing and has included a number of different names: ONJ - osteonecrosis of the jaw as a general description; BRONJ - bisphosphonate-related ONJ, indicating the drug class related to the necrosis; BIONJ - bisphosphonateinduced ONJ, assuming the causal role of the drug; ARONJ antiresorptive-related $\mathrm{ONJ}$, which expands the relation to all types of antiresorptive treatment; and MRONJ - medicationrelated ONJ, recently recommended in the AAOMS position paper, ${ }^{22}$ in order to include ONJ caused by any type of drug. Based on this development, the authors prefer the official term "MRONJ" but, in this paper, will use the short and popular term "ONJ". If not otherwise specified, the term ONJ is used in this paper interchangeably with MRONJ or BRONJ.

\section{Etiology and pathogenesis of $\mathrm{ONJ}$}

The etiology and pathogenesis of ONJ are complex and partly unknown. ONJ development is believed to be based on a combination of local and systemic risk factors. Bisphosphonates block the RANKL receptors on the osteoclasts, whose inhibition results in a reduced remodeling of the skeletal bones and an increase in the mineral content. Denosumab has a different mode of action but a comparable final inhibitory effect on the osteoclasts and subsequently, on the bones. The mystery is why the osteonecrosis occurs exclusively in the jaws? It is believed that the general bone turnover is more intensive in the alveolar process of the jaws than in other parts of the skeleton. Also, a hypothesis that genetic factors may play a role is under investigation. ${ }^{46,47}$ Recently, an important role of oral infections and low $\mathrm{pH}$ has been emphasized as a key factor in the development of ONJ lesions..$^{43,48}$ 


\section{Current reporting of $\mathrm{ONJ}$ in Denmark, Norway, and Sweden}

A formal institutional framework for monitoring ONJ in Scandinavia currently exists only within national regulatory agencies that publish aggregate numbers of cases originating from mandatory spontaneous reporting of ONJ by health care providers as a side effect of medication (Denmark: $h t t p: / / s u n d-$ hedsstyrelsen.dk/da/medicin/sikkerhed/bivirkninger/meld-enbivirkning, Norway: http://www.relis.no/Bivirkninger, Sweden: https://e-service.lakemedelsverket.se/formservice/formDownl oad?serviceName=biverkningsrapport tr lakemedelsverket). Underreporting of ONJ is likely if the health care professionals do not register all cases of ONJ., ${ }^{5,49}$ By November 28, 2013, the Danish Medicines Agency had received 95 case reports of ONJ potentially related to antiresorptive treatment. However, in a telephone survey in Denmark as of May 1, 2013, involving all six Danish hospital departments of oral and maxillofacial surgery, 308 known cases of ONJ were reported (authors' unpublished data). Between January 2003 and September 2010, the Norwegian Medicines Agency received reports of 51 ONJ cases potentially related to antiresorptive treatment, whereupon a study by Kruger et al revealed substantial underreporting based on an e-mail survey of all active members of the Norwegian Association of Oral and Maxillofacial Surgeons. ${ }^{5}$ As of July 2013, the total number of antiresorptive therapy-related ONJ cases reported to the Norwegian Medicines Agency increased to 119. The sudden increase in reported cases over 3 years may reflect both prevalent and incident ONJ cases, indicating a potential backlog of unreported cases. According to the Medical Products Agency in Sweden, 119 ONJ cases were reported in 2013. ${ }^{5}$ Based on a survey of oral and maxillofacial surgery clinics and hospital dental clinics in Sweden, ${ }^{49}$ the incidence rate of BRONJ per 100,000 patient-years was estimated at 67 in 2007 and at 69 in 2008. By December 2013, the Medical Products Agency in Sweden had received reports of 156 cases of ONJ potentially related to antiresorptive treatment (Olsson J, Enheten för
Läkemedelssäkerhet, Sweden, personal communication, 2014). Table 1 illustrates the current official reporting of ONJ authorities to the health authorities in Scandinavia. The number of reported cases represents $64 \%$ of the known documented cases, suggesting substantial underreporting.

\section{Methods}

The Scandinavian ONJ Cohort was established to support an ongoing regulator-mandated post-authorization safety study (PASS) of denosumab, $120 \mathrm{mg}$ every 4 weeks, in Denmark, Norway, and Sweden, with clinically confirmed ONJ as a primary safety endpoint. Because there existed no reliable diagnostic code-based algorithm to identify ONJ from the registry records $\mathrm{s}^{6,8}$ and because of country-specific referral patterns that do not always imply reporting to national patient registries, direct registration of incident ONJ cases at the patient's contact with the treating oral and maxillofacial surgeons became necessary. To ensure that the registration of the ONJ cases occurred independently of the identification of patients for the PASS of antiresorptive treatment, a systematic registration procedure of all $\mathrm{ONJ}$ cases in the three countries was launched, giving rise to the Scandinavian ONJ Cohort, comprising aggregated results of three national databases. The long-term purpose of the cohort extends beyond supplying safety information for a single study. It is envisioned that in the long term, the cohort will serve as a research tool for the identification of risk factors, treatment outcomes, and prognosis of ONJ. The purpose of the Scandinavian ONJ Cohort is to collect, detect, assess, monitor, treat, and ultimately, help prevent ONJ. The mission of the Scandinavian ONJ Cohort is thus to enable the development of evidence-based best care of patients affected by ONJ in the Scandinavian countries and beyond.

\section{Organization}

The denosumab PASS giving rise to the Scandinavian ONJ Cohort is carried out by the Department of Clinical

Table I Officially reported ONJ cases in Scandinavia by late 2014 and ONJ cases enrolled to the Scandinavian Cohort by September 2014

\begin{tabular}{|c|c|c|c|c|}
\hline Country & $\begin{array}{l}\text { Reporting } \\
\text { month and year }\end{array}$ & Authority & $\begin{array}{l}\text { Reported ONJ cases } \\
\text { to the authority }\end{array}$ & $\begin{array}{l}\text { ONJ cases in the present cohort } \\
\text { as per September I, 2014 }\end{array}$ \\
\hline Denmark & November 2013 & $\begin{array}{l}\text { Danish Medicines Agency, Danish } \\
\text { Health and Medicines Authority }\end{array}$ & 95 & 195 \\
\hline Norway & July 2013 & Norwegian Medicines Agency & $119 *$ & 110 \\
\hline Sweden & December 2013 & Medical Products Agency & 156 & 100 \\
\hline Total & & & 370 & 405 \\
\hline
\end{tabular}

Note: *The Norwegian Medicines Agency and RELIS emphasize that spontaneous adverse drug reactions are reported on suspicion, and do not document a causal relationship between a drug and adverse reaction.

Abbreviation: ONJ, osteonecrosis of the jaw. 
Epidemiology, Aarhus University, Denmark, in collaboration with the Cancer Registry of Norway, Oslo University Hospital, in Norway, and Karolinska University Hospital, in Sweden. The ONJ task force, established within that study and charged with the development of the cohort, includes the Scandinavian coordinator and three country coordinators, all of whom are authors of this manuscript (MS, SEN, BBH, CLW). All coordinators are senior-level oral and maxillofacial surgeons with a special interest and expertise in treatment of ONJ. The task force utilizes the established network of the national Danish, Norwegian, and Swedish professional associations as well as the Scandinavian Association of Oral and Maxillofacial Surgery, for establishing relevant information platforms for cohort enrollment.

\section{The Scandinavian setting: population and health care}

Denmark, Norway, and Sweden have a combined population of more than 20 million people. ONJ referral and treatment patterns are partially determined by geography, with care highly centralized to six hospital-based departments in Denmark, where distances between ONJ departments are short. In contrast, the setting in Norway is characterized by a higher prevalence of local and nonhospital-based clinics owing to their long north-to-south geographic axes (Table 2). In Sweden, hospital-based departments of oral and maxillofacial surgery as well as departments of hospital dentistry may handle the ONJ patients. The establishment of the national ONJ research databases that contribute data to the Scandinavian ONJ Cohort entailed detailed survey to identify clinics and departments of oral and maxillofacial surgery and oral medicine and hospital dentistry (hereafter, "ONJ clinics") that diagnose and treat ONJ cases in Denmark, Norway, and Sweden. Data collection is more time-consuming and involves contacting more clinics in Norway and Sweden than in Denmark due to larger country sizes and greater distances between the clinics (Tables 2 and 3). The geographical distribution of the oral and maxillofacial surgery clinics in the different countries is demonstrated in Figure 1.

Table 2 Denmark, Norway, and Sweden: basic demographic and geographic data

\begin{tabular}{llll}
\hline Country & $\begin{array}{l}\text { Population } \\
(\text { million) }\end{array}$ & $\begin{array}{l}\text { Area } \\
\left.\mathbf{( k m}^{\mathbf{2}}\right)\end{array}$ & $\begin{array}{l}\text { Distance from } \\
\text { north to south } \mathbf{( k m )}\end{array}$ \\
\hline Denmark & 5.6 & 43,000 & 358 \\
Norway & 5.1 & 324,000 & 1,790 \\
Sweden & 9.6 & 450,000 & 1,572 \\
Total & 20.3 & 878,000 & \\
\hline
\end{tabular}

Table 3 Numbers of departments and units of oral and maxillofacial surgery in Denmark, Norway, and Sweden (November 2013)

\begin{tabular}{lllll}
\hline & Denmark & Norway & Sweden & Total \\
\hline $\begin{array}{l}\text { Department/unit of oral } \\
\text { and maxillofacial surgery } \\
\text { (university/hospital) }\end{array}$ & 6 & $18^{*}$ & 33 & 56 \\
$\begin{array}{l}\text { Department of oral } \\
\text { medicine/general }\end{array}$ & 0 & 0 & 51 & 55 \\
$\begin{array}{l}\text { dentistry (hospital) } \\
\begin{array}{l}\text { Clinic of oral and } \\
\text { maxillofacial surgery } \\
\text { (private office) }\end{array}\end{array}$ & $23^{* *}$ & $65^{* * *}$ & $<5^{\#}$ & 88 \\
\begin{tabular}{l} 
Total \\
\hline
\end{tabular} & 29 & 83 & 84 & 199 \\
\hline
\end{tabular}

Notes: *Includes departments and units of oral surgery and oral medicine; **the Danish private clinics/offices refer their ONJ patients to one of the six departments of oral and maxillofacial surgery; $* * *$ includes private dental clinics with an attending specialist in oral and maxillofacial surgery and oral medicine on a regular basis. Some of the surgeons attend more than one clinic; "does not include private clinics with attendance of specialist in oral and maxillofacial surgery.

Abbreviation: ONJ, osteonecrosis of the jaw.

\section{Denmark}

Denmark is divided into five geographical administrative regions, each responsible for the health care delivery to its population. Four regions have one, and one region has two

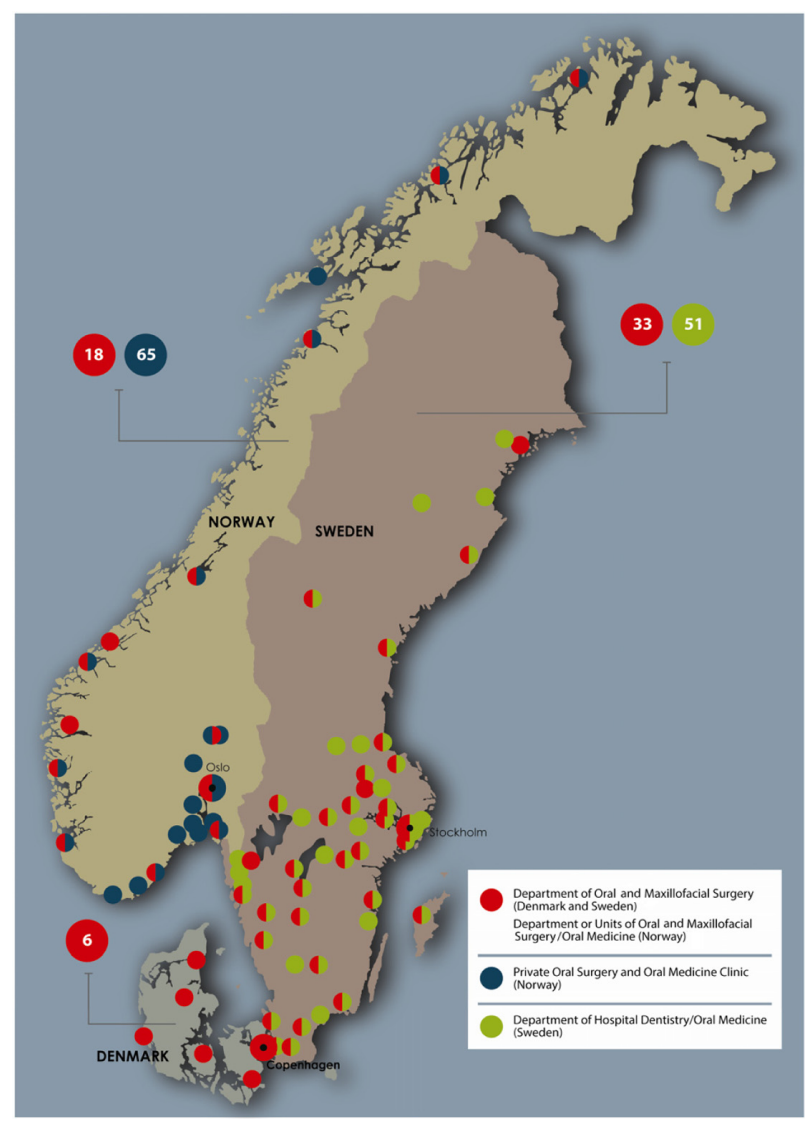

Figure I Map of ONJ clinics in Denmark, Norway and Sweden.

Notes: In Denmark there are 6 departments of oral and maxillofacial surgery taking care of ONJ patients (red). In Norway there are 18 departments/larger clinics of oral and maxillofacial surgery (red) and 65 private oral surgery and oral medicine clinics. In Sweden there are 33 departments of oral and maxillofacial surgery (red) and $5 \mathrm{I}$ departments of hospital dentistry/oral medicine (green). 
hospital departments of oral and maxillofacial surgery that treat ONJ. Thus, ONJ care is centralized in six hospitals. The country's 23 private oral and maxillofacial surgery clinics may receive ONJ cases but generally refer them to the six hospital-based departments (Figure 1 and Table 3). All six clinics have allocated a contact person.

\section{Norway}

Norway is divided into 19 counties (fylker), which, in turn, are divided into a total of 428 municipalities or kommuner. Norway differs from Denmark and Sweden in organization and education system for oral and maxillofacial surgery; one based on dentistry (oral surgery and oral medicine) and one on medicine (cranio-maxillofacial surgery). There are 18 hospital- or university-based departments/units of oral and maxillofacial surgery, and most of the units are attended by only a few specialists in oral surgery and oral medicine (Figure 1 and Table 3). All the clinics have appointed a contact person. A majority of the surgeons work in private offices, and some regularly attend at more than one clinic. They may encounter and manage patients with ONJ, at least the less advanced cases. All these surgeons have been contacted and are willing to report ONJ cases. This is important since ONJ cases, managed at private clinics only, are not reported to the National Patient Registry of Norway, complicating identification of these ONJ cases, even if and when uniform coding algorithms are developed.

\section{Sweden}

Sweden is divided into 21 counties, which, in turn, consist of 290 municipalities or kommuner. There are 33 departments of oral and maxillofacial surgery, 51 departments of oral medicine/general dentistry, and a few private offices/ clinics for oral and maxillofacial surgery. As of August 2014,
63 departments/clinics have appointed a contact person. The private offices are, in general, staffed by publically employed oral and maxillofacial surgeons working part time (Figure 1 and Table 3). The organization of the clinics may vary depending on geographical location; for example, a unit that officially counts as one clinic may, in fact, have several minor annex clinics that are perceived by patients as separate units.

\section{Patient flow and data collection to the national $\mathrm{ONJ}$ databases}

All identified ONJ clinics in the three countries are invited to participate in the ONJ research database and to allocate a contact person. Procedures for the data collection vary between the three countries and between the different clinics due to different organizations of the departments of oral and maxillofacial surgery. The common process of patient enrollment is illustrated in Figure 2. At each ONJ clinic, the contact person is responsible for obtaining the information in the ONJ registration form to be sent to the national coordinator or directly enrolled electronically into the database. Longitudinally, all ONJ cases related to antiresorptive treatment seen at the clinics will be reported to the Scandinavian ONJ Cohort.

\section{Data collection and variables}

The process of developing the ONJ database study, including the setup, and developing the registration forms and the subsequent communication to the clinics have led to a better understanding of diagnostic procedures and classification of ONJ in the three countries.

The Scandinavian ONJ task force met regularly over the past 3 years to calibrate knowledge level based on difficult ONJ cases. As a result of this process, we developed a common registration form in order to collect comparable

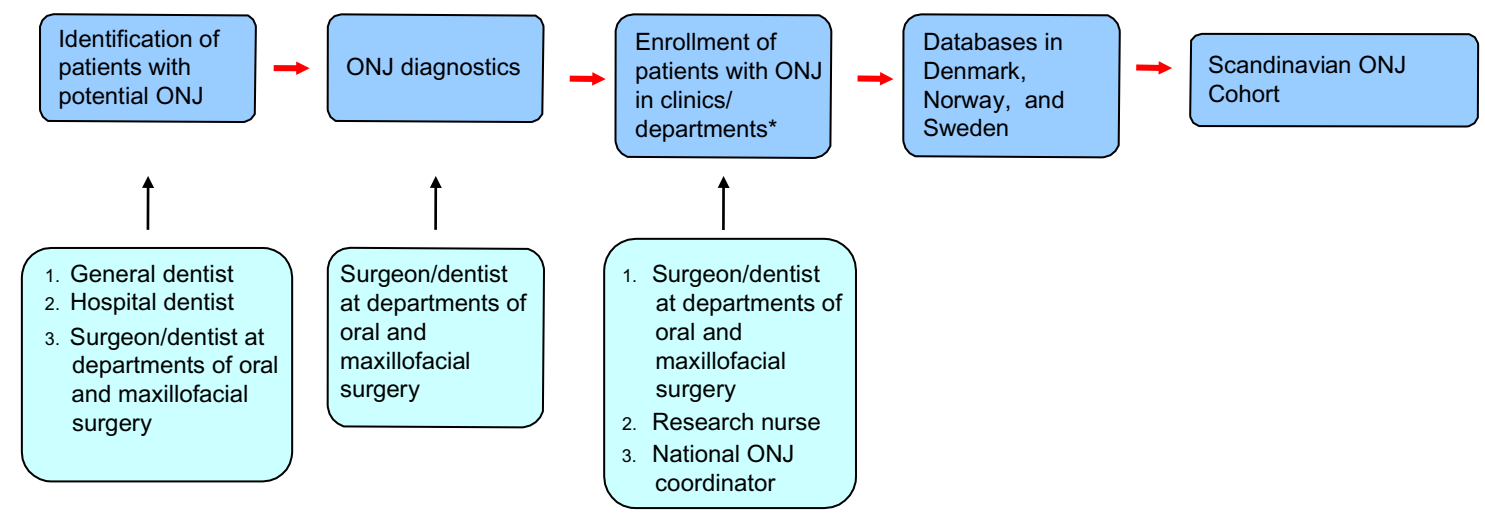

Figure 2 Flow chart of identification, diagnosis, enrolling and reporting $\mathrm{ONJ}$ in the three countries. Note: *Clinics/units/departments of oral and maxillofacial surgery and hospital dentistry (Sweden). Abbreviation: ONJ, osteonecrosis of the jaw. 
Table 4 List of the fields recorded in the database for each ONJ patient

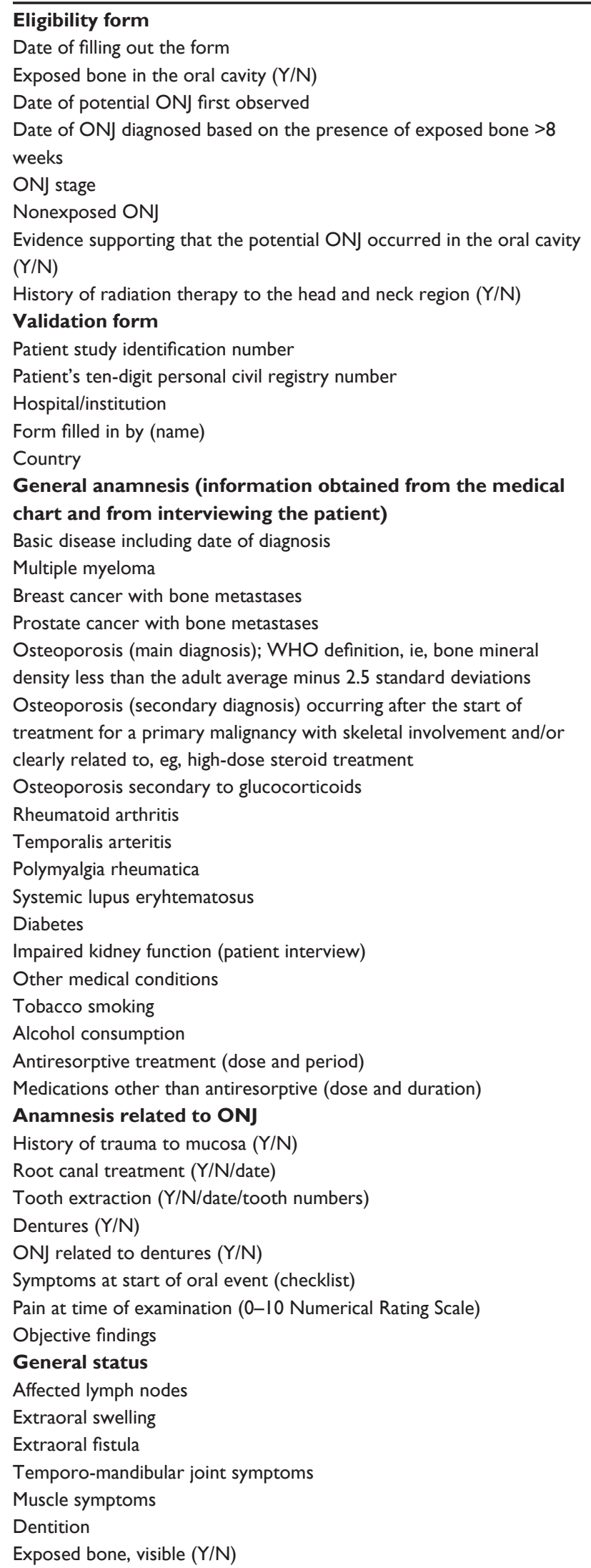

(Continued)
Table 4 (Continued)

Exposed bone by probing ( $\mathrm{Y} / \mathrm{N})$

Number, location, and size of bone lesions

Clinical findings related to bone lesions

Diagnostic tests

Imaging (type and date)

Histology

Radiological findings

Diagnoses, ICD-10 codes

Procedures

Type, date, and outcome

Antibiotic treatment (type, period, and effect)

Oral antiseptics (type, period, and effect)

Current status at follow-up visits (repeated minimum once a year)

Date

Status of ONJ (resolved/not resolved)

Pain (0-10 NRS)

Ongoing symptoms

Stage of ONJ

Abbreviations: ONJ, osteonecrosis of the jaw; Y, yes; N, no; WHO, World Health Organization; ICD- I0, International Classification of Diseases version 10.

data from the three different countries. The final registration form has approximately 60 data fields for each patient. Inclusion and exclusion criteria are defined, and data are obtained of patient demographics, medical history, previous and present medication, oral health history, oral clinical findings, and results of imaging, including radiographs and computed tomography scans (Table 4). The information on comorbidity is obtained from the medical charts or by interviewing the patient (whenever possible).

\section{Communication}

To establish the ONJ research databases, we undertook targeted information dissemination to the ONJ clinics in the three countries. This included information pamphlets and targeted presentations at the annual meetings of each of the three national associations of oral and maxillofacial surgery in 2012, 2013, and 2014 and at the biennial meeting of the Scandinavian Association of Oral and Maxillofacial Surgery in 2013, as well as other meetings involving the relevant medical specialties. At the enrollment start, an invitation to participate was sent to all ONJ clinics. In Denmark, a coordinator conducted a site visit to each unit and provided detailed introduction to the database procedures. In Norway, identification and registration of $\mathrm{ONJ}$ are done by directly contacting each surgeon and clinic, and by ICD-10 code searches at hospitals. It is hoped that increased awareness about the database study may result in referrals of ONJ cases to university and hospital departments and units, which may facilitate $\mathrm{ONJ}$ identification. If treating surgeons are unable to complete the registration form, the Norwegian ONJ research 
team conducts site visits to collect the relevant information on each ONJ case. A paper version of the registration form is available as the alternative to the electronic data entry. A study website http://www.onj.no has been developed, including an online questionnaire for dentists and surgeons to alert the ONJ coordinator of new cases. In Sweden, a website http://www.onj.nu was published at the study start containing information about the study, patient registration procedure, and coordinator contact information. The website has an electronic submission form for study participation, whereby the contact person at each clinic may request and receive an automatically generated individual username and password. The online registration can then be implemented. Several clinics requested help with the registration procedure at their clinic. In such cases, the ONJ task force coordinator has spent time at the clinic to demonstrate the registration process. The site is linkable from the Swedish Society for Oral and Maxillofacial Surgeons (http://www.kkf.nu) and from the Swedish Society of Orofacial Medicine (http://www.som.nu). The http://www.onj.nu site also contains links to literature about antiresorptive agents and ONJ, and a link to the Swedish Medical Products Agency. The X-ray images/files are generally separated from the medical charts in a different data system that requires a separate login process. All three databases in Denmark, Norway, and Sweden have identical data fields, corresponding to the registration form, but the data entry interface varies (Figure 3).

\section{Access to the research databases}

The Danish ONJ database is hosted by the Department of Clinical Epidemiology at Aarhus University, and a web-based recording of data can be accessed by the members of the study group for research approved by the Danish Data Protection Board. Access to the database by external researchers requires

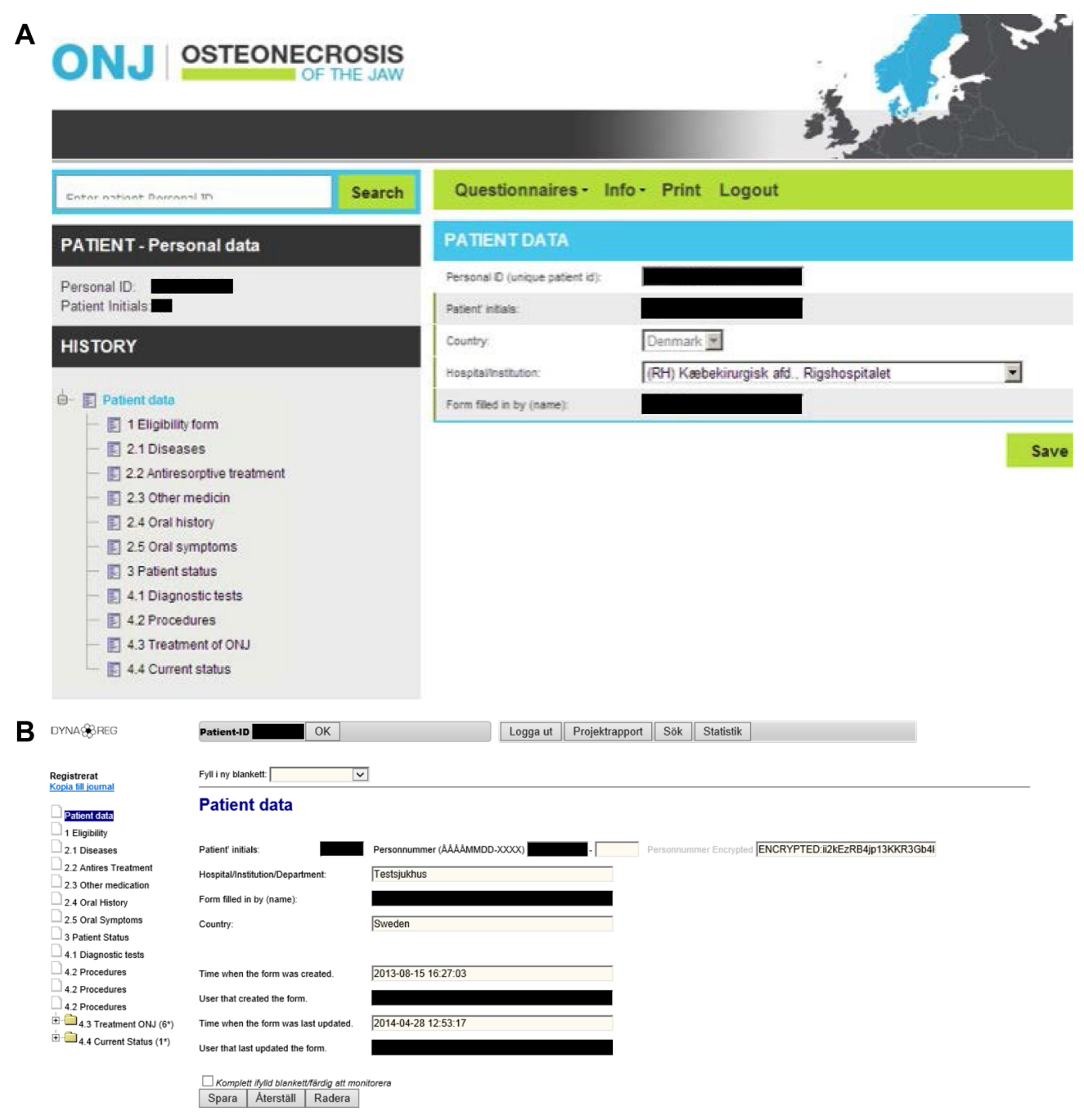

Figure 3 Print of the front pages of the ONJ registration forms in (A). Denmark and Norway, (B). Sweden.

Notes: (A) Denmark/Norway: front page of the patient registration form; (B) Sweden: front page of the patient registration form. 
permission from the responsible investigators and from the Danish Data Protection Board. The Norwegian database is hosted by the Faculty of Dentistry, University of Oslo and the web-based recording of data can be accessed by the study members. The Swedish database is hosted by the Department of Clinical Epidemiology at the Karolinska Institute/University Hospital, Solna. Contact persons at the clinics can get access to their own data.

\section{Data protection}

The maintenance of the research databases at the hosting institutions complies with the country-specific data protection laws, regulations, and current approvals. The establishment of a national time-limited ONJ database was approved by the Danish Data Protection Agency and the Danish National Board of Health in Denmark (record number 2012-41-0045), the regional Ethical Committee in Norway (2013/1053/REK sør-øst C), and by the regional Ethical Review Board in Sweden (Dnr 2013/319-31/2).

\section{Discussion}

The established Scandinavian ONJ collaboration takes advantage of an ongoing PASS in Denmark, Norway, and Sweden by sharing the research infrastructure. We anticipate that the Scandinavian ONJ Cohort will capture nearly all ONJ cases related to antiresorptive treatment in the three countries during the recruitment period. The continued data input will provide up-to-date data on the clinical course, risk factors, and therapy of ONJ. Furthermore, the national research databases establish a natural collaboration among the departments of oral and maxillofacial surgery and clinics treating ONJ patients in the three countries, improving care through better professional exchange and level of knowledge of ONJ management in the primary sector. The communication between oral and maxillofacial surgeons and oncologists, hematologists, urologists, endocrinologists, and private practitioners is of great importance. There is a need for continuous updates and reports of clinical observations and experiences among colleagues for improvement of knowledge about ONJ handling. The oral and maxillofacial surgeons need to follow the course of antiresorptive agents and new treatment regimens for different skeletal disorders. It is envisioned that the Scandinavian ONJ Cohort will also have an educational value by promoting interdisciplinary exchange, beneficial for patient care.

\section{Strengths and limitations}

The strengths of the Scandinavian ONJ Cohort collaboration include prospective and uniform data collection in three countries. The process of establishing the national databases that are the fundament for the cohort has led to increased knowledge of ONJ among oncologists, private dentists, oral maxillofacial surgery specialists, and especially, among the dedicated ONJ clinics. The three countries have stable societies, with well-functioning universal health care systems. Each individual carries a unique personal identifier, facilitating identification for enrollment and linkage of data from all national registries for epidemiologic research. Relatively low mobility (emigration $<0.1 \%)^{50-52}$ and complete registration of migrations and vital status facilitate longitudinal study designs with complete follow-up. Furthermore, the databases are useful tools for implementing large-scale ONJ studies including treatment trials in the future.

Potential underreporting by clinics into the database is an important limitation of the databases, as it may lead to underestimation of ONJ risk in the population. At the same time, point-of-referral capture of ONJ cases is a great improvement compared with registry-based monitoring, with associated ICD-10 codes repeatedly showing suboptimal validity to identify true ONJ cases. ${ }^{6-8}$ We will continuously benchmark reporting completeness by obtaining country-specific incidence rates of ONJ. The launch and maintenance of the Scandinavian ONJ Cohort involve a continuous quality assessment process, which may lead to adjustment of communication and improvement of the recording in all the ONJ clinics. The Scandinavian ONJ Cohort is a tool, which, over time, will help overcome underreporting.

The establishment of this project has been a resourceintensive effort, requiring time, IT expertise, and input from clinical, statistical, and epidemiologic research groups. There is thus a challenge to finance and secure resources for the continuity of the maintenance of the research databases and associated studies.

\section{Conclusion}

We established a Scandinavian ONJ collaboration to enable the identification of individuals with a clinically verified ONJ related to antiresorptive treatment for enrollment to the Scandinavian ONJ Cohort. Research based on the collected data will help better understand this debilitating condition, ultimately for the benefiting of care and outcomes of patients with ONJ. Furthermore, the study will increase the awareness among health care professionals of ONJ risk factors, which may help avoid its underdiagnosing and undertreatment. Given the importance of this condition, often associated with substantial patient suffering and discomfort, gaps in knowledge 
about its prognosis, and documented underreporting and shortcomings of ICD-10-based algorithms, there is a need for establishing systematic research databases with universal and prospective registration of ONJ cases. The Scandinavian countries, with universal health care, more or less centralized treatment of ONJ, established communication between treating surgeons, and possibility of long-term and complete follow-up, offer the ideal environment for establishing such infrastructure.

\section{Acknowledgments}

The following persons are thanked for helpful assistance: research nurse Ida Roelsgaard, Department of Oral and Maxillofacial Surgery, Rigshospitalet, Copenhagen, Denmark; Emma Fernandez, graphical designer, Department of Oral and Maxillofacial Surgery, Rigshospitalet, Copenhagen, Denmark; research nurse Anne Margrethe Dahlerup, Department of Oral and Maxillofacial Surgery, Aarhus University Hospital, Aarhus, Denmark; Morten Flink of ITMedico, Aarhus, Denmark; research physician Svein Hansen, Cancer Registry of Norway, Oslo University Hospital, Norway; Olof Akre, Clinical Epidemiology Unit, Department of Medicine, Karolinska Institute, Solna and Department of Urology, Karolinska University Hospital, Stockholm, Sweden; Anders Kjellman, Department of Clinical Science, Intervention and Technology, Karolinska Institute, Stockholm, Sweden and Department of Urology, Karolinska University Hospital, Stockholm, Sweden; Christofer Lagerros, Lagerros IT AB, Stockholm, Sweden; Chanelle Stirling, study administrator, Gothia Forum, Sahlgrenska University Hospital, Gothenburg, Sweden.

\section{Disclosure}

The EMA-mandated PASS of denosumab (http://clinicaltrials. gov/show/NCT01967160), for which the ONJ research databases were developed, is carried out by the Department of Clinical Epidemiology, Aarhus University Hospital, Denmark, according to its contract with Amgen Inc. All authors are salaried employees of their respective departments and institutions. MS, CLW, BBH, KMG, and SEN receive compensation through contracts with Aarhus University for their roles as collaborators on the PASS. The authors report no other conflicts of interest in this work.

\section{References}

1. Marx RE. Pamidronate (aredia) and zoledronate (zometa) induced avascular necrosis of the jaws: a growing epidemic. J Oral Maxillofac Surg. 2003;61(9):1115-1117.

2. Ruggiero SL, Mehrotra B, Rosenberg TJ, Engroff SL. Osteonecrosis of the jaws associated with the use of bisphosphonates: a review of 63 cases. J Oral Maxillofac Surg. 2004;62(5):527-534.
3. Migliorati CA, Woo SB, Hewson I, et al. A systematic review of bisphosphonate osteonecrosis (BON) in cancer. Support Care Cancer. 2010; 18(8):1099-1106.

4. Smith MR, Saad F, Coleman R, et al. Denosumab and bone-metastasisfree survival in men with castration-resistant prostate cancer: results of a phase 3, randomised, placebo-controlled trial. Lancet. 2012;379(9810): 39-46.

5. Kruger TB, Sharikabad MN, Herlofson BB. Bisphosphonate-related osteonecrosis of the jaw in four Nordic countries and an indication of under-reporting. Acta Odontol Scand. 2013;71(6):1386-1390.

6. Bergdahl J, Jarnbring F, Ehrenstein V, et al. Evaluation of an algorithm ascertaining cases of osteonecrosis of the jaw in the Swedish national patient register. Clin Epidemiol. 2013;5:1-7.

7. Gammelager H, Erichsen R, Antonsen S, et al. Positive predictive value of the International Classification of Diseases, 10th revision, codes to identify osteonecrosis of the jaw in patients with cancer. Cancer Epidemiol. 2012;36(4):381-383.

8. Gammelager H, Svaerke C, Noerholt SE, et al. Validity of an algorithm to identify osteonecrosis of the jaw in women with postmenopausal osteoporosis in the Danish national registry of patients. Clin Epidemiol. $2013 ; 5: 263-267$.

9. Lo JC, O'Ryan FS, Gordon NP, et al. Prevalence of osteonecrosis of the jaw in patients with oral bisphosphonate exposure. J Oral Maxillofac Surg. 2010;68(2):243-253.

10. Solomon DH, Mercer E, Woo SB, Avorn J, Schneeweiss S, Treister N. Defining the epidemiology of bisphosphonate-associated osteonecrosis of the jaw: prior work and current challenges. Osteoporos Int. 2013;24(1):237-244.

11. Khosla S, Burr D, Cauley J, et al. Bisphosphonate-associated osteonecrosis of the jaw: report of a task force of the American society for bone and mineral research. J Bone Miner Res. 2007;22(10): 1479-1491.

12. Fehm T, Beck V, Banys M, et al. Bisphosphonate-induced osteonecrosis of the jaw $(\mathrm{ONJ})$ : incidence and risk factors in patients with breast cancer and gynecological malignancies. Gynecol Oncol. 2009;112(3): 605-609.

13. Allen MR, Burr DB. The pathogenesis of bisphosphonate-related osteonecrosis of the jaw: so many hypotheses, so few data. J Oral Maxillofac Surg. 2009;67(5 suppl):61-70.

14. Saad F, Brown JE, Van Poznak C, et al. Incidence, risk factors, and outcomes of osteonecrosis of the jaw: integrated analysis from three blinded active-controlled phase III trials in cancer patients with bone metastases. Ann Oncol. 2012;23(5):1341-1347.

15. Advisory Task Force on Bisphosphonate-Related Ostenonecrosis of the Jaws; AAOMS. American association of oral and maxillofacial surgeons position paper on bisphosphonate-related osteonecrosis of the jaws. J Oral Maxillofac Surg. 2007;65(3):369-376.

16. Ruggiero SL, Dodson TB, Assael LA, Landesberg R, Marx RE, Mehrotra B. American association of oral and maxillofacial surgeons position paper on bisphosphonate-related osteonecrosis of the jaw 2009 update. Aust Endod J. 2009;35(3):119-130.

17. Fedele S, Porter SR, D'Aiuto F, et al. Nonexposed variant of bisphosphonate-associated osteonecrosis of the jaw: a case series. Am J Med. 2010;123(11):1060-1064.

18. Bagan JV, Hens-Aumente E, Leopoldo-Rodado M, Poveda-Roda R, Bagan L. Bisphosphonate-related osteonecrosis of the jaws: study of the staging system in a series of clinical cases. Oral Oncol. 2012;48(8): 753-757.

19. Schiodt M, Reibel J, Oturai P, Kofod T. Comparison of nonexposed and exposed bisphosphonate-induced osteonecrosis of the jaws: a retrospective analysis from the Copenhagen cohort and a proposal for an updated classification system. Oral Surg Oral Med Oral Pathol Oral Radiol. 2014;117(2):204-213.

20. Lazarovici TS, Yahalom R, Taicher S, Elad S, Hardan I, Yarom N. Bisphosphonate-related osteonecrosis of the jaws: a singlecenter study of 101 patients. J Oral Maxillofac Surg. 2009;67(4): 850-855. 
21. AAOMS. American Association of Oral and Maxillofacial Surgeons. Position paper on medication-related osteonecrosis of the jaw; 2014 [cited July 16, 2014]. Available from: http://www.aaoms.org/members/ resources/aaoms-advocacy-and-position-statements/.

22. Fedele S, Bedogni G, Scolettea M, et al. Up to a quater of patients with osteonecrosis of the jaw associated with antiresorptive agents remain undiagnosed. Br J Oral \& Maxillofac Surg. Epub October 1, 2014.

23. Itzstein C, Coxon FP, Rogers MJ. The regulation of osteoclast function and bone resorption by small GTPases. Small GTPases. 2011;2(3): $117-130$.

24. Lacey DL, Boyle WJ, Simonet WS, et al. Bench to bedside: elucidation of the OPG-RANK-RANKL pathway and the development of denosumab. Nat Rev Drug Discov. 2012;11(5):401-419.

25. Fizazi K, Carducci M, Smith M, et al. Denosumab versus zoledronic acid for treatment of bone metastases in men with castration-resistant prostate cancer: a randomised, double-blind study. Lancet. 2011; 377(9768):813-822.

26. Henry DH, Costa L, Goldwasser F, et al. Randomized, double-blind study of denosumab versus zoledronic acid in the treatment of bone metastases in patients with advanced cancer (excluding breast and prostate cancer) or multiple myeloma. J Clin Oncol. 2011;29(9):1125-1132.

27. Recknor C, Czerwinski E, Bone HG, et al. Denosumab compared with ibandronate in postmenopausal women previously treated with bisphosphonate therapy: a randomized open-label trial. Obstet Gynecol. 2013;121(6):1291-1299.

28. Schwarz P, Rasmussen AQ, Kvist TM, Andersen UB, Jorgensen NR. Paget's disease of the bone after treatment with Denosumab: a case report. Bone. 2012;50(5):1023-1025.

29. Rizzoli R, Body JJ, Brandi ML, et al. Cancer-associated bone disease. Osteoporos Int. 2013;24(12):2929-2953.

30. Koch FP, Walter C, Hansen T, Jager E, Wagner W. Osteonecrosis of the jaw related to sunitinib. Oral Maxillofac Surg. 2011;15(1):63-66.

31. Fleissig Y, Regev E, Lehman H. Sunitinib related osteonecrosis of jaw: a case report. Oral Surg Oral Med Oral Pathol Oral Radiol Endod. 2012;113(3):e1-e3.

32. Estilo CL, Fornier M, Farooki A, Carlson D, Bohle G 3rd, Huryn JM. Osteonecrosis of the jaw related to bevacizumab. J Clin Oncol. 2008;26(24):4037-4038.

33. Greuter S, Schmid F, Ruhstaller T, Thuerlimann B. Bevacizumab-associated osteonecrosis of the jaw. Ann Oncol. 2008;19(12):2091-2092.

34. Guarneri V, Miles D, Robert N, et al. Bevacizumab and osteonecrosis of the jaw: incidence and association with bisphosphonate therapy in three large prospective trials in advanced breast cancer. Breast Cancer Res Treat. 2010;122(1):181-188.

35. Hopp RN, Pucci J, Santos-Silva AR, Jorge J. Osteonecrosis after administration of intravitreous bevacizumab. J Oral Maxillofac Surg. 2012;70(3):632-635.

36. Katsenos S, Christophylakis C, Psathakis K. Osteonecrosis of the jaw in a patient with advanced non-small-cell lung cancer receiving bevacizumab. Arch Bronconeumol. 2012;48(6):218-219.
37. Serra E, Paolantonio M, Spoto G, Mastrangelo F, Tete S, Dolci M. Bevacizumab-related osteneocrosis of the jaw. Int J Immunopathol Pharmacol. 2009;22(4):1121-1123.

38. Bettini G, Blandamura S, Saia G, Bedogni A. Bevacizumab-related osteonecrosis of the mandible is a self-limiting disease process. BMJ Case Rep. 2012;22:2012.

39. Vahtsevanos K, Kyrgidis A, Verrou E, et al. Longitudinal cohort study of risk factors in cancer patients of bisphosphonate-related osteonecrosis of the jaw. J Clin Oncol. 2009;27(32):5356-5362.

40. Yamashita J, McCauley LK. Antiresorptives and osteonecrosis of the jaw. J Evid Based Dent Pract. 2012;12(3 Suppl):233-247.

41. Van den Wyngaert T, Delforge M, Doyen C, et al. Prospective observational study of treatment pattern, effectiveness and safety of zoledronic acid therapy beyond 24 months in patients with multiple myeloma or bone metastases from solid tumors. Support Care Cancer. 2013;21(12):3483-3490.

42. Brufsky AM, Sereika SM, Mathew A, Tomifumi O, Singh V, Rosenzweig M. Long-term treatment with intravenous bisphosphonates in metastatic breast cancer: a retrospective study. Breast J. 2013;19(5): 504-511.

43. Otto S, Schreyer C, Hafner S, et al. Bisphosphonate-related osteonecrosis of the jaws - characteristics, risk factors, clinical features, localization and impact on oncological treatment. J Craniomaxillofac Surg. 2012;40(4):303-309.

44. Yamazaki T, Yamori M, Ishizaki T, et al. Increased incidence of osteonecrosis of the jaw after tooth extraction in patients treated with bisphosphonates: a cohort study. Int J Oral Maxillofac Surg. 2012;41(11): 1397-1403.

45. Beuselinck B, Wolter P, Karadimou A, et al. Concomitant oral tyrosine kinase inhibitors and bisphosphonates in advanced renal cell carcinoma with bone metastases. Br J Cancer. 2012;107(10):1665-1671.

46. Raje N, Woo SB, Hande K, et al. Clinical, radiographic, and biochemical characterization of multiple myeloma patients with osteonecrosis of the jaw. Clin Cancer Res. 2008;14(8):2387-2395.

47. Sarasquete ME, Garcia-Sanz R, Marin L, et al. Bisphosphonate-related osteonecrosis of the jaw is associated with polymorphisms of the cytochrome P450 CYP2C8 in multiple myeloma: a genome-wide single nucleotide polymorphism analysis. Blood. 2008;112(7):2709-2712.

48. Otto S, Pautke C, Opelz C, et al. Osteonecrosis of the jaw: effect of bisphosphonate type, local concentration, and acidic milieu on the pathomechanism. J Oral Maxillofac Surg. 2010;68(11):2837-2845.

49. Ulmner M, Jarnbring F, Torring O. Osteonecrosis of the jaw in Sweden associated with the oral use of bisphosphonate. J Oral Maxillofac Surg. 2013;72(1):76-82.

50. Statistics Denmark. 2014. Available from: http://www.dst.dk. Accessed September 9, 2014

51. Statistics Norway. 2014. Available from: http://www.ssb.no. Accessed September 9, 2014.

52. Statistics Sweden. 2014. Available from: http://www.scb.se. Accessed September 9, 2014.
Clinical Epidemiology

\section{Publish your work in this journal}

Clinical Epidemiology is an international, peer-reviewed, open access, online journal focusing on disease and drug epidemiology, identification of risk factors and screening procedures to develop optimal preventative initiatives and programs. Specific topics include: diagnosis, prognosis, treatment, screening, prevention, risk factor modification,

Submit your manuscript here: http://www.dovepress.com/clinical-epidemiology-journal

\section{Dovepress}

systematic reviews, risk \& safety of medical interventions, epidemiology \& biostatistical methods, and evaluation of guidelines, translational medicine, health policies \& economic evaluations. The manuscript management system is completely online and includes a very quick and fair peer-review system, which is all easy to use. 